\title{
Investor Attention and Growth Anomalies in NASDAQ Stocks-Evidence from Google Trend Volume
}

\author{
Ya Li*, Raymond Chan, John Tsang \\ LSK School of Business and Administration, The Open University of Hong Kong, Ho Man Tin, Hong Kong \\ Email address: \\ yali@ouhk.edu.hk(Ya Li),kpchan@ouhk.edu.hk(Raymond Chan),kmtsang@ouhk.edu.hk(John Tsang) \\ ${ }^{*}$ Corresponding author
}

To cite this article:

Ya Li, Raymond Chan, John Tsang. Investor Attention and Growth Anomalies in NASDAQ Stocks-Evidence from Google Trend Volume. Journal of Finance and Accounting. Vol. 8, No. 5, 2020, pp. 238-245. doi: 10.11648/j.jfa.20200805.15

Received: September 24, 2020; Accepted: October 15, 2020; Published: October 26, 2020

\begin{abstract}
We study the effects of investor attention on the capital investment anomaly on NASDAQ stocks. Based on total asset growth, researchers find firms that substantially increase capital investments subsequently achieve negative benchmarkadjusted returns. On one hand, some scholars propose that investors incorrectly underreact to the empire building behavior of managers who aggressively increase investment expenditure. On the other hand, some scholars argue that investors appear to overreact to past firm growth rates. We aim to determine whether the growth anomaly is due to underreaction or overreaction in this research. We apply Google Search Volume Index as a new direct measure of investor attention to provide empirical evidence for under-reaction and over-reaction explanations of the total asset growth anomaly on NASDAQ stocks. We adopt double sorting and Fama-MacBeth regression and find the stock prices rise up when investors search actively of the underlying stock tickers. The anomaly is stronger when investors are extremely overreacting and underreacting. When investors are rational or calm down, this total asset growth effect disappears. Our empirical design disentangles the dilemma that whether the strand of growth anomalies is due to risk or mispricing. Within proponents of mispricing, our research innovatively tease out of the opposing explanations of under-reaction and over-reaction as the relevant driver of the growth anomalies.
\end{abstract}

Keywords: Attention, Google Search, Total Asset Growth

\section{Introduction}

We study the effects of investor attention on crosssectional stock market anomalies. We examine how the attention of retail investors (via Google search volume) affects the strength of these anomalies. We use an abnormal increase (or decrease) in attention as a proxy for overreaction (or underreaction). If an anomaly does not respond to abnormal changes in attention (the null hypothesis), then we interpret it as being consistent with the default risk explanation of rational pricing, which is that investing in high-risk stocks will provide a higher return. If, however, the anomalies do respond to abnormal change in attention, then it means that mispricing is the major driver. Within the theoretical model of mispricing, we will look at whether underreaction or overreaction is driving the result, as overreaction-based (or underreaction-based) mispricing theory predicts that anomalies will be stronger following an abnormal increase (or decrease) in attention. Our study will shed light on the current debate of as to whether risk or mispricing is a better explanation of the anomalies we have found in our data.

We observe how investors' under- and overreaction to information affects capital investment anomalies. It has been difficult for traditional asset-pricing models such as the capital asset pricing model (CAPM), arbitrage pricing theory (APT) or intertemporal capital asset pricing model (ICAPM) to explain the growing set of anomalies. Due to this, some papers including Barberis, Shleifer and Vishny (1998) and Daniel, Hirshleifer and Subrahmanyam (1998) studied this topic from a behavioral perspective. Through behavioral perspective, both underreaction and overreaction can explain this hypothesis. However, we are unable to identify which one of these is more compelling. We study nine asset growth or investment anomalies, namely total asset growth, accounting accruals, net operating assets, abnormal capital expenditure, investment growth, investment-to-assets ratio, investment-to-capital ratio, net share issuance and composite 
share issuance $[4,7,15,21,25,29,30,32]$. We aim to study the interaction between abnormal investor attention and anomalies for NASDAQ stocks. Duan et al find the relation between FinTech attention and its sector returns [8].

\subsection{Rational Interpretations of the Anomalies}

Rational interpretations suggest that attention may not affect the anomalies. According to these interpretations, anomaly strategies give higher returns because they are riskier. Q-theory of asset pricing model has been used by Hou, Xue, and Zhang (2015) in order to explain how abnormal return predictabilities are basically risk premiums which have been omitted in the earlier factor models [16]. Q-theory has an assumption that financial managers try to maximize the expected value of the firm by choosing positive NPV projects. The theory also implies that growth of a firm is negatively related to expected returns. Besides this, Fama and French have added two more factors to its famous model [11]. Now along with risk, size, and book to market value, profitability and investment are also the factors of this model. Here, investment factor tells us about the growth anomalies. Gross profit scaled by assets factor describe the profitability anomalies $[1,3,12]$. The valuation equation from this model indicates that there is a negative relationship between expected returns and growth or investment. This model does not explain this negative relationship due to which we cannot distinguish if it follows rational pricing or mispricing theory.

\subsection{Mispricing Interpretations of the Growth Anomalies: Under-reaction vs. Over-reaction}

Spread in anomalies driven by underreaction implies that anomalies are stronger when there is an abnormal drop in attention. Managers often have an empire building behavior in which they aggressively increase their investment expenditures. When investors have a slow response to this behavior, underreaction occurs. According to an argument from Titman, Wei and Xie, agency problem might be the reason why these managers irrationally raise capital and increase investment expenditures [30]. This means that rather than thinking to benefit the firm, the managers invest for their own benefit. These investments from the empire building behaviors however send optimistic signals to the investors who incorrectly overvalue the firms' prices. Due to this, unjustified excessive investments occur which make it likely that these firms will underperform their benchmark in the coming five years. Thus with time, prices decrease and valuation comes to a rational level. This shows us that relation between initial capital expenditures and their subsequent returns is strongly negative.

Contrary to the previous view, spread in anomalies from overreaction implies that abnormal increase in attention causes anomalies to be stronger. When past high asset growth is postulated far into the future and an increasing trend in stock price is generalized by the investors, overreaction occurs. According to Cooper, Gulen and
Schill, investors often overreact to firms' past growth rates [4]. At current period, stock prices stay above the rational level because investors generalize the past good performance of high growth stocks. However, only a few growth firms can continue to have an increasing growth rate. The cash flows, future earning, etc. of most of the firms are much lower than their past level. Due to this, a decrease in stock price in the future is observed. These growth anomalies tend to be stronger when there is a more serious overreaction.

\subsection{Current Problems the Literature Faces}

According to Mashruwala, Rajgopal, and Shevlin and Lipson, Mortal, and Schill, growth anomalies measured by accounting accruals and total asset growth respectively, are stronger in firms that have higher limits to arbitrage [20, 22]. This finding is consistent with mispricing theory. On the other hand, $\mathrm{Li}$ and Zhang indicate that there is a stronger negative relation between growth and expected returns when investment frictions from q-theory of asset pricing are more severe. Lam and Wei found that there is a substantially positive correlation between the empirical proxies of limits to arbitrage and investment frictions [19]. Lam et al show that empirical proxies of limits-to-arbitrage and those of investment frictions are substantially positively correlated in the updated sample [18]. Thus, when growth anomalies are stronger along higher limits to arbitrage, they are also consistent with rational pricing under the q-theory. Moreover, when we control proxies for investment frictions, the relation between total asset growth anomalies with measure of limits to arbitrage becomes much weaker. Therefore, it still puzzles current literature if growth anomalies occur due to risk or mispricing. Even for mispricing, there is confusion on whether these growth anomalies occur due to overreaction or underreaction. Our paper therefore aims to help in figuring out which theory is consistent with growth anomalies.

\section{Data}

This section describes our variables and data. We focus on stocks traded on NYSE, Amex and Nasdaq. Their annual financial statements and monthly stock information are from Compustat and the Center for Research in Security Prices (CRSP), respectively. Like Fama and French, certificates, American depositary receipts (ADRs), shares of beneficial interest (SBIs), unit trusts, closed-end funds, real estate investment trusts (REITs), and financial firms are excluded $[9,10]$. We delete a firm year for which we do not have sufficient data to compute the necessary characteristics at each portfolio formation. We use delisting returns to mitigate the survivorship bias. ${ }^{1}$

\footnotetext{
1 Shumway (1997) suggests that the returns of stocks delisted for poor performance (delisting codes 500 and 520 to 584) are usually unavailable [27]. Following Shumway and Warther (1999), when the return is missing for an available CRSP month date, we use the delisting return wherever available [28].
} 


\subsection{Proxies of Retail Investor Attention}

Da, Engelberg and Gao propose a novel and direct measure of investor attention using aggregate search frequency in Google search engine [6]. First, using Google Trends (http://www.google.com/trends), weekly Search Volume Index (SVI) of a search term is the number of searches for that term scaled by its time-series average. Gao et al further use this measure to study investor sentiment globally [14]. This paper measures abnormal change in the SVI as a proxy for an attention shock:

$$
A S V I_{i, t}=\frac{S V I_{i, t}-A V G S V I_{i \mid t-12, t-1}}{S D A V G S V I_{i \mid t-12, t-1}}
$$

where $A V G S V I_{i \mid t-12, t-1}$ and $S D A V G S V I_{i \mid t-12, t-1}$ are the mean and standard deviation of the VI for stock $i$ over the past 12 months, respectively. A stock with an increase (decrease) in SVI relative to its past 12-month average is regarded as having more (less) attention

i. For each stock with valid growth or profitability measure, define the search keyword to be the stock's (A) ticker symbol, (B) trade name, (C) full legal company name, or (D) name of main product of the company.

a. The search by the firm's ticker symbol is most likely to represent an interest in the stocks' financial information. The ticker symbol is already available from Compustat together with the growth or profitability measure. Yet we will have to examine and manually adjust the tickers as Compustat back modifies the tickers when change in business or listing status of the firm occurs over time. E.g., CP\&L Energy changed its name to Progress Energy in December 2000 under a merger agreement with Progress Energy. Thus, the ticker "CPL" of CP\&L Energy for fiscal year 2001 from Compustat has to be revised to "PGN" to reflect the correct symbol at that time.

b. A ticker symbol might be noisy, i.e., it might coincide with common English word that tends to represent objects not related to the firm traded with the symbol. E.g., the ticker of 4Licensing Corp was "FOUR" for fiscal year 2005. The Google search records of the keyword "FOUR" would more likely represent attention paid to Arabic numeral 4, Four Season Hotel or album Four by One Direction. Da, Engelberg, and Gao suggest we should remove firms with such tickers for robustness check [6]. Yet we might still able to meaningfully observe attention through the Google search records for the firm using keywords based on its trade name "4Licensing" or full legal name "4Licensing Corp".

c. The company name is also available from Compustat. Again, we will have to examine and manually adjust the names as Compustat back modifies the names when change in business or listing status of the firm occurs over time. Taking the example of Avant Immunotherapeutics, the name "AVANT IMMUNOTHERAPEUTICS-OLD" of the company for fiscal year 2004 from Compustat has to be revised to "AVANT IMMUNOTHERAPEUTICS" to reflect

When delisting return is not available, we use $-30 \%$ for poor performance delisting and $0 \%$ for other cases. the correct name at that time. This name was also the trade name and full legal company name.

d. In some cases, Compustat does not provide the exact full legal company name. E.g. the name "ROCKY MOUNTAIN CHOC FACT INC" is recorded in the database for Rocky Mountain Chocolate Factory INC for fiscal year 2004 while the correct full name should be "ROCKY MOUNTAIN CHOCOLATE FACTORY INC". We also need to create the trade name "ROCKY MOUNTAIN CHOCOLATE FACTORY" for this firm for that period.

e. Alternatively, we follow Da, Engelberg, and Gao to identify the main product of a company from Nielsen Media Research as the most advertised product of the company during a period according to the Nielsen database [5]. The name of the main product name will be hand merged to the firm.

ii. We use program to retrieve Google Search Volume Index for each keyword during each period between January of calendar year $\mathrm{t}$ to June of calendar year $\mathrm{t}+1$ since 2004 . Based on the information provided by Google Trends, the absolute numbers represent search interest relative to the highest point on the chart. If at most $10 \%$ of searches for the given region and period were for "GOOG," we would consider this 100. This does not convey absolute search volume. The change or trend in the index over time during fixed period is comparable across stocks in the cross section after consulting with several IT professionals and doctoral researchers specializes on web crawling, online data collection, and big data processing.

\subsection{Anomalies}

We have constructed the below nine growth measures. The definitions of anomalies are presented in Appendix 1.

Anomaly 1: Asset growth effect. Cooper, Gulen, and Schill find that firms that decrease their total assets have higher future abnormal stock returns [4].

Anomaly 2: Accounting accruals effect. Sloan shows that firms with high accruals earn abnormal lower returns than firms with low accruals [29].

Anomaly 3: Net operating assets effect. Hirshleifer, Hou, Teoh, and Zhang document that firms with higher net operating assets have lower abnormal return than firms with lower net operating assets [15].

Anomaly 4: Abnormal capital expenditure effect. Titman, Wei, and Xie find that firms with high capital expenditure have lower abnormal return than firms with lower capital expenditure [30].

Anomaly 5: Investment growth effect. Xing documents portfolios of firms with low investment growth rates (IGRs) have significantly higher average returns than those with high IGRs [32].

Anomaly 6: Investment-to-assets ratio effect. Lyandres, Sun, and Zhang find lower abnormal return of high investment-to-assets ratio stocks [21].

Anomaly 7: Investment-to-capital ratio effect. Xing [32] shows that high investment-to-capital ratio predicts abnormally lower future returns [32]. 
Anomaly 8: Net share issuance effect. Pontiff and Woodgate (2008) document share issuance can be used to forecast stock returns in the cross-section. Firms with net positive share issuance have lower returns [25].

Anomaly 9: Composite share issuance effect. Daniel and Titman (2006) find that firms that issue shares under-perform nonissuers [7].

We measure the change in attention from year t-1 January to year $\mathrm{t}$ June. We form the anomalies portfolios at year $t$ June and calculate anomalies spread based on twelve monthly return until year $\mathrm{t}+1$ June. The anomalies portfolios are rebalanced annually in June.

\section{Methodology}

The test methods include double sorting and FamaMacBeth regression [13]. As limits-to-arbitrage and investment frictions measures are designed to test mispricing theory for market anomalies in the extant literature, we first run the correlation check between the investor attention and proxies for limits-to-arbitrage and investment frictions. If the correlation are weak (in magnitude or statistical significance), then we do not control for the limits-toarbitrage and investment frictions. The test is designed as below.

To measure the extreme change in attention, we group stocks into five groups of attention based on the two standard deviations around the average attention in the cross section. If the attention is less than the average attention level by two standard deviations, firms are belonging to underreaction group. Within underreaction group, we separate firms into weak underreaction group and strong underreaction group using median level of underreaction as the breakpoint. Similarly, firms are belonging to overreaction group if the attention is more than the average attention level by two standard deviations. Within overreaction group, we separate firms into weak overreaction group and strong overreaction group using median level of overreaction as the breakpoint.

Fama and French document the five factors model including market, size, value, profitability and investment patterns [12]. As we study profitability and investment anomalies, we will estimate the risk adjusted return control for market, size and value variables by using market, size and value excess returns. We calculate value-weighted returns based on market capitalization and equal-weighted returns from the end of June of calendar year $t$ to end of June of calendar $\mathrm{t}+1$. We construct a long-short strategy in each change in attention categories, with the long (short) leg being the high-performing (low-performing) quintile. The strength of anomalies is measured by the return spread of the longshort strategy. We compare the return spread between lowest change in attention level and highest change in attention level to check whether anomalies are stronger in underreaction category or overreaction category or irresponsive to attention level.

Alternatively, after forming the attention groups, instead of sorting stocks into quintiles according to a growth or profitability measure, we estimate the Fama-Mac Beth regression of future returns on a growth or profitability measure and controls among each of the five groups [13]. We then examine how the return-growth slope varies across the attention groups.

$$
\begin{gathered}
\text { Ret }_{i, t}=a_{0}+a_{1} \text { Anomaly }_{i, t}+b_{0} \Delta \text { Attention }_{i, t} \\
+b_{1} \text { Anomaly }_{i, t} \\
+\Delta \text { Attention }_{i, t}+c_{1} \beta_{i, t}+c_{2} \text { Size }_{i, t} \\
+c_{3} B / M_{i, t}
\end{gathered}
$$

Anomaly, $\beta$, Size and B/M are the firm characteristics. The $\Delta$ Attention is the change in SVI. The coefficients (state the slope, e.g., $a_{1}$ ) on anomalies should be consistent with extant literature, namely negative for total asset growth, total accruals, net operating assets, abnormal capital expenditure, investment growth, investment-to-assets, investment-tocapital, net share issuance and composite share issuance but positive for gross profitability and operating profit.

\section{Empirical Results}

The table 1 demonstrates the summary statistics for above nine growth anomalies. For each of the anomalies, we obtain value-weighted portfolio returns within each decile of the anomaly's sorting variable. A long-short strategy is constructed using the extreme deciles, 1 and 10. Panel A reports the mean, standard deviation and $10^{\text {th }}, 25^{\text {th }}, 50^{\text {th }}, 75^{\text {th }}$, and $90^{\text {th }}$ percentile of anomalies. The average return for total asset growth, total accrual, net operating assets, abnormal capital expenditure, investment growth, investment-to-assets, investment-to-capital, net share issuance, composite share issuance, are $0.176,-0.044,0.487,-0.019,0.274,0.059$, $0.381,0.004$ and 0.307 respectively. These anomalies have standard deviations of $0.345,0.070,0.299,0.560,0.858$, $0.112,0.306,0.096$ and 0.568 respectively.

Panel B show the correlation among the nine anomalies. The correlations among the anomalies are low except for net operating assets and total asset growth. Their correlation is 0.47. The correlation between investment growth and abnormal capital expenditure is 0.64. The correlation between investment-to-capital ratio and abnormal capital expenditure is 0.57 . The correlation between investment-tocapital ratio and investment growth is 0.60 .

Panel A reports the time-series average of summary statistics of total asset growth (TAG), total accrual (Accruals), net operating assets (NOA), abnormal capital expenditure (ACAPEX), investment growth (IG), investment-to-assets (IA), investment-to-capital (IK), net share issuance (NSI) for the fiscal year ending year $t-1$, or composite share issuance (CSI) for the five years ending at June of year $\mathrm{t}$. Stdev is the standard deviation. $25 \%$ and $75 \%$ refer to the $25^{\text {th }}$ and $75^{\text {th }}$ percentiles respectively. Panel B reports the time-series averages of annual cross-sectional correlations among the asset growth variables. Correlations that are significant at 5\% level are in bold. 
Table 1. Summary statistics and sample correlations.

Panel A. Summary statistics

\begin{tabular}{|c|c|c|c|c|c|c|c|}
\hline & Mean & Stdev & Min & $25 P$ & Median & $75 P$ & $\operatorname{Max}$ \\
\hline TAG & 0.176 & 0.345 & -0.606 & 0.028 & 0.108 & 0.238 & 4.809 \\
\hline Accrual & -0.044 & 0.070 & -0.502 & -0.070 & -0.040 & -0.014 & 0.423 \\
\hline NOA & 0.487 & 0.299 & -0.508 & 0.306 & 0.491 & 0.649 & 3.369 \\
\hline ACAPEX & -0.019 & 0.560 & -1.000 & -0.305 & -0.076 & 0.192 & 7.786 \\
\hline IG & 0.274 & 0.858 & -0.810 & -0.136 & 0.119 & 0.443 & 9.690 \\
\hline IA & 0.059 & 0.112 & -0.770 & 0.012 & 0.037 & 0.078 & 1.410 \\
\hline NSI & 0.004 & 0.096 & -0.728 & -0.028 & 0.001 & 0.019 & 1.494 \\
\hline CSI & 0.307 & 0.568 & -0.831 & -0.073 & 0.097 & 0.604 & 2.931 \\
\hline
\end{tabular}

Panel B. Sample correlations

\begin{tabular}{|c|c|c|c|c|c|c|c|c|c|}
\hline & (1) & (2) & (3) & (4) & (5) & (6) & (7) & (8) & (9) \\
\hline (1) $T A G$ & 1.00 & & & & & & & & \\
\hline (2) Accruals & 0.02 & 1.00 & & & & & & & \\
\hline (3) $N O A$ & 0.47 & 0.20 & 1.00 & & & & & & \\
\hline (4) $A C A P E X$ & -0.02 & 0.00 & -0.07 & 1.00 & & & & & \\
\hline (5) $I G$ & 0.17 & 0.07 & -0.02 & 0.64 & 1.00 & & & & \\
\hline (6) $I A$ & 0.47 & -0.23 & 0.22 & 0.09 & 0.15 & 1.00 & & & \\
\hline (8) NSI & 0.61 & 0.01 & 0.00 & 0.00 & 0.11 & 0.17 & 0.12 & 1.00 & \\
\hline (9) $C S I$ & 0.28 & 0.13 & 0.01 & 0.01 & 0.09 & 0.09 & 0.22 & 0.25 & 1.00 \\
\hline
\end{tabular}

Table 2 displays the mean monthly ASVI portfolio returns for each of the asset growth anomaly groups. When comparing returns across asset growth portfolios, the attention effect is confirmed as strong when investors are either overreaction or underreaction. For underreaction group, the return difference between the low- and highgrowth portfolios is positive and significant at 5\% level. The high-minus-low return is $2.122 \%$. For overreaction group, the return difference between low- and high-growth portfolios is positive and significant at $10 \%$ level. The high-minus-low return is $1.268 \%$. However, the return premium is negative when investors are rational. When investors are neither overreacted nor underreacted, we cannot find the asset growth anomaly. This finding is consistent with the behavioral story of asset growth anomalies. When investors response slowly to the empire building behavior of managers, the negative relationship between asset growth and stock return is pronounced. When investors postulate past high asset growth far into the future and generalize an increasing trend in stock prices, the negative relationship between asset growth and stock return is pronounced.

At the end of each month over the sample period, stocks are horizontally sorted into quantiles by ASVI. The low (high) portfolio is the decile that contains stocks with the lowest (highest) level of ASVI. Stocks are vertically sorted into quantiles by asset growth measures. The raw denoted High - Low is the return difference between the high- and low-asset growth portfolios. The $t$-statistics listed in parentheses are estimated based on Newey-West standard errors [23]. The superscripts *, **, and *** indicate statistical significance at the $10 \%, 5 \%$, and $1 \%$ levels, respectively.

Table 2. Main Test Double Sort.

\begin{tabular}{llllll}
\hline Ret & \multicolumn{5}{c}{ Attention } \\
\hline Growth & $\mathbf{1}$ & $\mathbf{2}$ & $\mathbf{3}$ & $\mathbf{4}$ & $\mathbf{5}$ \\
\hline 1 & 0.743 & 0.937 & 2.360 & 1.860 & 0.805 \\
2 & 0.595 & 1.936 & 1.189 & 2.075 & 1.591 \\
3 & 1.354 & 1.732 & 2.476 & 2.087 & 2.216 \\
4 & 1.011 & 1.192 & 2.019 & 1.336 & 2.035 \\
5 & 2.865 & 1.220 & 1.121 & 2.834 & 2.073 \\
High-Low & 2.122 & 0.283 & -1.239 & 0.974 & 1.268 \\
t-stats & $2.18 * *$ & 0.66 & -1.65 & 1.05 & $1.93 *$ \\
\hline
\end{tabular}

Table 3 reports the estimation results. As for $a_{1}$, all regressions demonstrate a negative relationship between asset growth and expected returns. As for the $b_{0}$, when people actively search for the stock tickers, the stock prices normally will get up. For this test, the slope coefficient on Anomaly $_{i, t} * \Delta$ Attention $_{i, t}\left(b_{1}\right)$ is of interest. When the cross-sectional regressions are estimated by OLS, total asset growth, investment-to-capital, net share issuance and composite share issuance show a negative sign which is consistent with the underreaction-based hypothesis. Total accruals, net operating assets, abnormal capital expenditure, investment growth and investment-to-assets show a positive sign which is consistent with the overreaction-based hypothesis.

This table reports the estimated slope coefficients $a_{1}, b_{0}$ and $b_{1}$ of the Fama-MacBeth regression

$$
\begin{gathered}
\text { Ret }_{i, t}=a_{0}+a_{1} \text { Anomaly }_{i, t}+b_{0} \text { A } \text { Attention }_{i, t} \\
+b_{1} \text { Anomaly }_{i, t} * \Delta \text { Attention }_{i, t}+c_{1} \beta_{i, t}+c_{2} \text { Size }_{i, t} \\
+c_{3} B / M_{i, t}
\end{gathered}
$$


where $R_{i, t}$ is the monthly stock return between the end of June of year $t$ to the end of June of year $t+1$. Anomaly is an asset growth measure, including total asset growth (TAG), total accrual (Accruals), net operating assets (NOA), abnormal capital expenditure (ACAPEX), investment growth (IG), investment-to-assets (IA), investment-to-capital (IK), net share issuance (NSI) for the fiscal year ending year $t-1$, or composite share issuance (CSI) for the five years ending at June of year $t$. Detailed definitions of variables are provided in the Appendix. All right-hand-side variables are winsorized at the $0.5^{\text {th }}$ percentile and the $99.5^{\text {th }}$ percentile. The $t$-statistics (t-stat) are based on the Newey-West robust standard errors with autocorrelations up to 12 lags and reported in parentheses. The sample period of monthly returns is from the end of June of 1963 to the end of December of 2017. The superscripts $*, * *$, and $* * *$ indicate statistical significance at the $10 \%, 5 \%$, and $1 \%$ levels, respectively.

Table 3. Main Test Regression.

\begin{tabular}{|c|c|c|c|c|c|c|c|c|}
\hline $\mathbf{y}$ & Estimation method & $\mathbf{a}_{1}$ & t-stat & $\mathbf{b}_{0}$ & t-stat & Anomaly & $\mathbf{b}_{1}$ & t-stat \\
\hline \multirow{8}{*}{$\begin{array}{l}\text { Stock } \\
\text { Returns }\end{array}$} & Regression 1 & -1.109 & $-2.32 * *$ & 0.397 & $4.38 * * *$ & TAG & 0.223 & $2.83 * * *$ \\
\hline & Regression 2 & -2.425 & -1.43 & 0.426 & $4.53 * * *$ & Accruals & -0.245 & $-2.20 * *$ \\
\hline & Regression 3 & -0.852 & $-2.04 * *$ & 0.635 & $3.76 * * *$ & NOA & -0.382 & $-3.33 * * *$ \\
\hline & Regression 4 & -0.322 & -1.52 & 0.441 & $5.61 * * *$ & ACAPEX & -0.286 & $-3.76 * * *$ \\
\hline & Regression 5 & -0.396 & $-2.87 * * *$ & 0.454 & $5.53 * * *$ & $\mathrm{IG}$ & -0.07 & $-1.78^{*}$ \\
\hline & Regression 6 & -2.825 & $-2.57 * * *$ & 0.454 & $4.90 * * *$ & IA & -0.320 & -1.40 \\
\hline & Regression 7 & -1.353 & $-3.47 * * *$ & 0.429 & $3.26 * * *$ & IK & 0.024 & 1.08 \\
\hline & Regression 9 & -0.185 & -0.92 & 0.409 & $4.21 * * *$ & CSI & 0.069 & 1.48 \\
\hline
\end{tabular}

In regression one, when the growth anomaly is measured by total asset growth (TAG), the relationship between expected returns and total asset growth is negatively significant at $5 \%$ level. When people search more stock, the returns are significantly higher at $1 \%$ level. The coefficient on the interaction term is 0.223 which is significant at $1 \%$ level. It indicates the total asset growth anomaly is more significant when investors are overreacting to the past growth.

In the regression two, when we use accruals to measure the growth anomaly, a negative relationship between expected returns and accruals is observed although it is not significant. However, we can still observe that more attention leads to higher returns. The interaction coefficient is negatively significant at 5\% level. It supports the underreaction-based hypothesis.

Regression three uses net operating assets (NOA) in order to calculate the growth anomaly. Here the relationship between the expected returns and the net operating assets is negative with 5\% significance. Again, attention and expected returns have a positive relationship with $1 \%$ significance at tvalue 3.76. Conversely, interaction coefficient is negative with -0.382 value which makes it $1 \%$ significant. Thus, NOA anomaly is more significant when investors are underreacting to the empire building behavioral.

The forth regression gives us growth anomaly through Abnormal Capital Expenditure (ACAPEX). It has a negative relationship between Abnormal Capital Expenditure and expected returns. At $a_{1}$ equal to -0.322 , the results are not significant. On the other hand, more attention brings more expected returns and this positive relationship is $1 \%$ significant. Besides, interaction term is -0.286 with t-value 3.76 which makes it negatively $1 \%$ significant. So there is more significance to the ACAPEX anomaly when there is an underreaction.

In regression five, Growth Anomalies are calculated by using Investment Growth (IG). Here, a relationship between
Investment Growth and Expected Returns has a negative relationship which is negatively significant at $1 \%$. Increase in attention brings increased expected returns which are positively significant at $1 \%$. Interaction term gives us a $\mathrm{t}$ value of -1.78 which gives a negative $10 \%$ significance. This negative relationship proves that IG anomaly supports hypothesis of underreaction.

Through regression six, Investment to Assets (IA) helps us get the growth anomalies. The relationship between Investment to Assets and Expected Returns is negative at $1 \%$ significance. The significance is calculated from its $t$ value 2.57. There is a positive relationship between investor attention and the expected returns. This relationship is given by value 0.454 of $b_{0}$ which is $1 \%$ significant. However the coefficient of interaction is -0.320 which is not significant. The negative sign shows that IA anomaly follows an underreaction hypothesis.

From seventh regression, growth anomalies are provided from Investment to Capital (IK). Through this regression, the relationship between Investment to Capital and Expected Returns is negative at $1 \%$ significance. Attention is directly linked with the expected returns - more the attention gives more expected returns and vice versa. This relationship has tvalue 3.26 which makes it positively significant at $1 \%$. Interaction is positive but is not significant. This means that there is an underreaction with weak significance.

We calculate growth anomaly from Net Share Issuance (NSI) in the eighth Regression. In this regression, relationship between Net Share Issuance and Expected Returns is seen to be negative. This relationship is not significant with $a_{1}$ equal to -0.821 . There is a positive attention to expected returns relationship with $1 \%$ significance and $t$ value 5.39. Moreover, positive 5\% significance can be seen when the interaction coefficient is 1.132. This positive sign suggests that investors' overreaction makes the NSI anomaly more significant.

In regression nine, Composite Share Issuance's (CSI) 
helps us get the growth anomaly. CSI's relationship with expected returns is negative as well as insignificant. Attention however has a $1 \%$ positive significance with a big $t$ value of 4.21 . This anomaly is not significant, but has a positive relationship with expected returns. With $t$ value equal to 1.48 , this anomaly follows overreaction hypothesis.

\section{Conclusion}

Our main contributions to the literature are threefold. First, most of the investor attention measure in the literature, e.g., extreme returns and trading volume, take the top down approach to proxy the market attention on a stock. By contrast, we take a new bottom up approach to measure market attention by combining the components of institutional investor attention, market professional attention, and retail investor attention. Thus, we are not only able to examine the attention effects of the overall market but also those of different market participants. Second, to our understanding, our project is the first to involve big data (Google Trends) together with conventional datasets to comprehensively study investor attention and the cross section of stock returns involving nine anomalies. Our study may provide new results to help distinguish between the rational interpretation and the mispricing interpretation of growth or investment anomalies. Finally, our research design may simultaneously provide new results to help distinguish between the under-reaction interpretation and the over-reaction interpretation of the set of growth anomalies.

\section{Appendix: Anomalies Description}

Anomaly 1: Asset growth effect

Growth in book value of total assets (TAG) is calculated as the change in total assets (item AT) over a fiscal year $t$ scaled by beginning total assets.

Anomaly 2: Total accruals effect

Accounting accruals (Accruals) is calculated as the change in non-cash assets (item AT less item CHE) less the change in nondebt liabilities (item LT less item DLTT less item DLC).

Anomaly 3: Net operating assets effect

Net operating assets (NOA) is calculated as the change in operating assets and operating liabilities over a fiscal year scaled by beginning total assets. Operating assets is total assets minus cash and short-term investments (item CHE). Operating liabilities is total assets less current liabilities (item DLC), long-term debt (item DLTT), minority interests (item MIB), preferred stocks (item PSTK), and common equity (item CEQ).

Anomaly 4: Abnormal capital expenditure effect

Abnormal capital expenditure (ACAPEX) is measured at the end of June of year $\mathrm{t}$ as $\left.\mathrm{CE}_{\mathrm{t}-1} /\left[\mathrm{CE}_{\mathrm{t}-2}+\mathrm{CE}_{\mathrm{t}-3}+\mathrm{CE}_{\mathrm{t}-4}\right] / 3\right]-1$, in which $\mathrm{CE}_{\mathrm{t}-\mathrm{j}}$ is capital expenditure (Compustat annual item CAPX) scaled by sales (item SALE) for the fiscal year ending in calendar year $\mathrm{t}-\mathrm{j}$.
Anomaly 5: Investment growth effect

Investment growth (IG) is measured for the portfolio formation year $t$ as the growth rate in capital expenditure (Compustat annual item CAPX) from the fiscal year ending in calendar year $\mathrm{t}-2$ to the fiscal year ending in $\mathrm{t}-1$.

Anomaly 6: Investment-to-assets effect

Investment-to-assets ratio (IA) is calculated as the change in inventories (item INVT) and gross property, plant, and equipment (item PPEGT) over a fiscal year scaled by beginning total assets.

Anomaly 7: Investment-to-capital effect

Investment-to-capital (IK) is the ratio of capital expenditure (Compustat annual item CAPX) to the net book value of fixed assets at the beginning of each fiscal year.

Anomaly 8: Net share issuance effect

Net share issuance (NS) is calculated as the natural logarithm of the ratio of split-adjusted shares (item $\mathrm{CSHO}$ multiplied by item ADJEX_C) outstanding at the end of a fiscal year to that at the beginning of the year.

Anomaly 9: Composite shares issuance effect

Composite shares issuance (CSI) measures the growth rate in the ME not attributable to the stock return, $\log \left(\mathrm{ME}_{\mathrm{t}} / \mathrm{ME}_{\mathrm{t}-5}\right)$ $-\mathrm{r}(\mathrm{t}-5, \mathrm{t}) . \mathrm{ME}_{\mathrm{t}}$ is the ME on the last trading day of June in year $\mathrm{t}$ from CRSP. $\mathrm{R}(\mathrm{t}-5, \mathrm{t})$ is the cumulative log return on the stock from the last trading day of June in year $\mathrm{t}-5$ to the last trading day of June in year t.

\section{Acknowledgements}

Ya Li acknowledges financial support from Research Grants Council of Hong Kong, Hong Kong PhD Fellowship Scheme [Grant PF13-13593]. The authors would like to thank KHAN Aman Attique for his research assistance for this article. All errors are ours.

\section{References}

[1] Ball, R., Gerakos, J., Linnainmaa, J. T. and Nikolaev, V. V., 2015. Deflating profitability. Journal of Financial Economics, 117 (2), pp. 225-248.

[2] Carhart, M. M., 1997. On persistence in mutual fund performance. Journal of Finance 52, 57-82.

[3] Chuan Ang, T., Lam, F. E. C., Ma, T., Wang, S. and Wei, K. J., 2019. What is the real relationship between cash holdings and stock returns?. International Review of Economics \& Finance, 64, pp. 513-528.

[4] Cooper, M. J., Gulen, H., Schill, M. J., 2008. Asset growth and the cross-section of stock returns. Journal of Finance 63, 1609-1651.

[5] Da, Z., Engelberg, J., Gao, P., 2010. In search of fundamentals. Working paper.

[6] Da, Z., Engelberg, J., Gao, P., 2011. In search of attention. Journal of Finance 66, 1461-1499.

[7] Daniel, K., Titman, S., 2006. Market reactions to tangible and intangible information, Journal of Finance 61, 1605-1643. 
[8] Duan, J., Liu, J. and Chen, Q., 2020. Research on the relationship between FinTech attention and its sector returns. International Journal of Economics, Finance and Management Sciences, 8 (1), p. 57.

[9] Fama, E. F., French, K. R., 1992. The cross-section of expected stock returns. Journal of Finance 47, 427-465.

[10] Fama, E. F., French, K. R., 1993. Common risk factors in the returns on stocks and bonds. Journal of Financial Economics $33,3-56$.

[11] Fama, E. F., French, K. R., 2014. A five-factor asset pricing model. Journal of Financial Economics 116, 1-22.

[12] Fama, E. F. and French, K. R., 2016. Dissecting anomalies with a five-factor model. The Review of Financial Studies, 29 (1), pp. 69-103

[13] Fama, E. F., MacBeth, J. D., 1973. Risk, return, and equilibrium: empirical tests. Journal of Political Economics $81,607-636$.

[14] Gao, Z., Ren, H. and Zhang, B., 2018. Googling investor sentiment around the world. Journal of Financial and Quantitative Analysis, Forthcoming.

[15] Hirshleifer, D., Hou, K., Teoh, S. H., Zhang, Y., 2004. Do investors overvalue firms with bloated balance sheets? Journal of Accounting and Economics 38 297-331.

[16] Hou, K., Xue, C., Zhang, L., 2015. Digesting anomalies: an investment approach. Review of Financial Studies 28, 650 705 .

[17] Lam, F. E. C., Li, Y., Prombutr, W. and Wei, K. J., 2020. Limits to arbitrage, investment frictions, and the investment effect: New evidence. European Financial Management, 26 (1), pp. 3-43.

[18] Lam, F. Y. E. C., Wei, K. C. J., 2011, Limits-to-arbitrage, investment frictions, and the asset growth anomaly, Journal of Financial Economics 102, 127-149.

[19] Li, D., Zhang, L., 2010. Does q-theory with investment frictions explain anomalies in the cross section of returns? Journal of Financial Economics 98, 297-314.

[20] Lipson, M. L., Mortal, S., Schill, M. J. 2011. On the scope and drivers of the asset growth effect. Journal of Financial and Quantitative Analysis 46, 1651-1682.

[21] Lyandres, E., Sun, L., Zhang L., 2008. The new issues puzzle: testing the investment-based explanation. Review of Financial Studies 21, 2826-2855.

[22] Mashruwala, C., Rajgopal S., Shevlin, T., 2006. Why is the accrual anomaly not arbitraged away? The role of idiosyncratic risk and transaction costs. Journal of Accounting and Economics 42, 3-33.

[23] Newey, W. K; West, K. D., 1987. A simple, positive semidefinite, heteroskedasticity and autocorrelation consistent covariance matrix. Econometrica 55, 703-708.

[24] Novy-Marx, R., 2013. The other side of value: the gross profitability premium. Journal of Financial Economics 108, 128.

[25] Pontiff, J., Woodgate, A., 2008. Share issuance and crosssectional returns. Journal of Finance 63, 921-954.

[26] Sharpe, W. F., 1964. Capital asset prices: a theory of market equilibrium under conditions of risk. Journal of Finance 19, 425-442.

[27] Shumway, T., 1997. The delisting bias in CRSP data. Journal of Finance 52, 327-340.

[28] Shumway, Tyler, and Vincent A. Warther, 1999. The delisting bias in CRSP's Nasdaq data and its implications for the size effect. Journal of Finance 54, 2361-2379.

[29] Sloan, R. G., 1996. Do stock prices fully reflect information in accruals and cash flows about future earnings? Accounting Review 3, 289-315.

[30] Titman, S., Wei, K. C. J., Xie, F., 2004. Capital investments and stock returns. Journal of Financial and Quantitative Analysis 39, 677-700.

[31] Wang, H., Yu, J., 2013. Dissecting the Profitability Premium. Working paper.

[32] Xing, Y., 2008. Interpreting the value effect through the qtheory: an empirical investigation. Review of Financial Studies 21 1767-1795. 